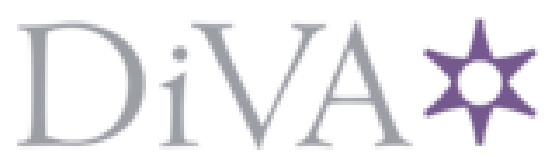

http://www.diva-portal.org

This is the published version of a paper presented at ICMT 2015 University of Defence Brno.

Citation for the original published paper:

Sivertun, Å. (2015)

Geographical Data for Training, Planning and Tactical Implementation.

In: IEEE ICMT2015: IEEE International Conference on Military Technologies IEEE

N.B. When citing this work, cite the original published paper.

Permanent link to this version:

http://urn.kb.se/resolve?urn=urn:nbn:se:fhs:diva-5818 


\title{
GeOgraPhicAl Data For TRAINING, PlanNING AND TACTICAL IMPLEMENTATION
}

\author{
ÅKE SIVERTUN \\ MVI/MTA Swedish Defence University (SEDU) \\ Stockholm, Sweden \\ Ake.sivertun@fhs.se
}

\begin{abstract}
Tactics are the part of the military problem solving, which attempts to address situations that arise in a concrete context and in a specific geographical area. It is about learning to perceive both the more stable geographical conditions in the working area as well as taking into consideration the effects of climate and weather and how the squad and their systems are affected and how an opponent could try to exploit these conditions and turn them to his advantage. The idea in tactical training is therefore to be able to master both the battlefield environment with its limitations and possibilities and the combat that is conducted there. Friction is used as a concept in several discussions about military activities. The geography with its sometimes channelling terrain and various landscape elements can constitute serious obstacles in trying to carry out all the tasks and abilities expected of a unit. Geography, Climate and Weather can thus be regarded as frictions in a military operation. This should also be possible to train in simulators and systems for war gaming.
\end{abstract}

Keywords-Tactical training, War-gaming, Geographical Information Systems, Geographical and Climatological frictions in Military operations

\section{INTRODUCTION}

Frictions are often used to describe the shortcomings in the own organisation Command, Control and Communication (C3) supply chain etc. Another notion of frictions consists of the opponent's ability to adapt their own tactics and take advantage of our vulnerabilities and turn them to their advantage which could ultimately determine who will win a conflict. Internal frictions may be difficult to coordinate as in integrating information and intelligence, leading and coordinating the activities; and ensuring that the military logistics supply the necessary support required for the operation. Furthermore, if problems exist with the systems that support the operation, or these are ineffective and not produce the desired effect at reasonable efforts in terms of material resources and personnel, as well as at low "social" costs as possible - these elements will only add to the existing frictions. Managing frictions and being able to coordinate and concentrate their own forces and efforts requires planning and tactical implementation. All of these skills must be trained and today more and more training is made in simulators. These simulators, however, often handle the geographical frictions to a minor degree. To what extent is this training then effective? To some predetermined pattern of events, one can learn to react quickly. This is done according
Kahneman in the so-called "Cognitive System I" [1]. According to Kahneman, we also have a "Cognitive System II" which is used when we need to consider more complex issues, make calculations and figure out the probability of different outcomes. The problem with this system is that it is slow and lazy. To support this type of deliberation and decision-making one must have the support of technical systems that keeps track of large amounts of data, complex relationships and rapid processes. A military campaign is just such a huge fast and complex system. In order to train to conduct such operations war games and simulations are important. In order to describe the balance between the requirements for education and experience, data and support systems, the Langefors "Infologic equation" can be used [2]. This report describes how geographical and climatological data, and information derived from those, are essential when practicing tactical decisionmaking.

\section{WHAT IS PLANNING OF TACTICAL OPERATIONS?}

One can interpret planning as a product - a plan - but also as a process of collecting relevant parameters for both strategic and tactical decisions. It is a question of a cooperation between different inter-service representatives and stakeholders in finding goals and solutions that are as realistic as possible. From an epistemological perspective, one can never be sure that a decision is the right one. This was studied in one of the Swedish Defence University's projects during which Berndt Brehmer addressed the "critique framework". Here the possibility of developing decision support that falsified various alternative decisions rather than systems that suggested a particular solution was discussed [3]. Planning has also been suggested as a self-synchronizing process by for example Brehmer [4] where he points out how the needs of focusing and convergence as in Albert's [5] and route selection and focusing as in Brehmer [6] (2007); can be solved even without a formal "Commander". The cases in which coordination, synchronization, and focus are required are situations where the task is too large or extensive to be met by only one branch of the service or function but requires input from multiple units. There may also be high dynamical situations that require simultaneous planning and action, or that the different units only in conjunction with sufficient resources are able to solve the task. There can even be situations where the individual units lack the pos- 
sibility to overview and understand-the totality of the situation, without obtaining extra information from other units. Selfsynchronization is sometimes cited as an option when no single commander has been mandated to decide over the entire operation.

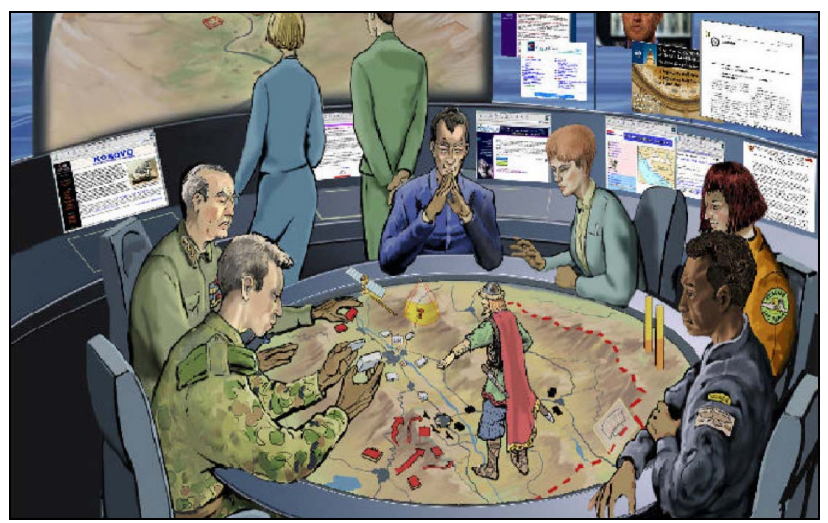

Figure 1. Digital maps as a tool to create shared situational awareness

Regardless the command philosophy a need to coordinate efforts requires a common situational awareness where the various representatives can contribute their views and can agree on what conditions are known and what sufficient knowledge is lacking in order to make educated and rational decisions and by that reason there is a need to assimilate additional intelligence about. What knowledge is then needed?

Börje Langefors formulated the Infologic equation in the 70 s in connection with research on pilots' information needs, and the ability to absorb information through the airborne computers that were developed for SAAB jet fighters at that time. This Information provided both flight data, external environmental data and functioned as an integral part of the system (Command, Control and Communication - C3).

$$
I=i(D, S, t)^{l}
$$

Information, $I$, to be dependent on the data, $D$, and the recipient's prior knowledge - $S$, sometimes also called the covering structure, by the interpretation process $i$, during the time at hand, $t$ :

This airborne information was not intended to be used in the same way as a ground-based system of tactical behaviour but still has relevance as it points out the importance of analysing the potential usefulness of the information conveyed. When designing an Information management system one must define what are critical tasks (information) which need to be conveyed to the user. To achieve this, one must decide not only what data should be included, but also the training and preconceptions the user must have to be able to assimilate the information. If it is a person who is used to determining the various technical instruments and knows what the different values represent then there is no need to explain them in such

${ }^{1}$ Langefors, B., Essays on Infology. Chartwell W Bratt. 1996. detail or if the user is accustomed to reading maps and additionally familiar with the landscape, detailed maps are then not required The processed data have been reformulated range from single Capta - (eg a radar echo or a time signal from a GNSS satellite) to Data (the merged time signals from several satellites that provide a coordinate) Information (when the coordinates are entered on a digital map so that one can define where one is located) Knowledge (is this place good or bad for my purposes) Wisdom (not to attack a target because it is a high risk of collateral damage that would discredit our mission - or to act contrary to current doctrine).

If the system either contains pre-classified data or functions that automatically validate the various statements; and if the system contains pre-classified data or functions that automatically validate the various statements and suggested interpretations; this then reduces information overload for the user. There may be reasons to consider how much and how processed the data or information should be when presented to the individual user. Methods to investigate what level of knowledge the user has, the purpose of the use, optimization of how long it will take to get "enough" reliable information, the user's language, domain-specific concepts, varying methods to represent or index data; or other characteristics of the modalities of how data are presented and other parameters of the infologic equation have been developed already. In information systems of the semantic-WEB type there are features of this and databases are semantically and ontologically indexed. Various features to manage, merge, analyse and present can then assist the user with the data/information at the right level and tailored to the given purpose. This should also be done at the right time - that is, within the decision window that is available in the current situation.

In normal cases various tasks have been predefined into those that are possible and reasonable, and analyses and presentations are then prepared for different service representatives' tasks and at different levels of management. Major decisions are not made by systems but constitute only decision support. Just, in the same way as it is stated on GPS-based navigation devices used on ships; these systems cannot replace good seamanship, or the way in which knowledgeable and critical users can detect if any information or functions are incorrect. On the other hand, no matter how clever and familiar the users are with a certain task, they do not manage the calculations and analyses that computers can help them with within the possible decision time frame which is required in highly dynamic and complex situations with a challenging opponent or in a full-blown crisis. In military - operations and protection systems, it is sometimes necessary to let the system decide to e.g. trigger countermeasures because it is impossible for a human to take that decision in time. What Capta - Data Information and Knowledge, does one need when training tactical behaviour and decision-making? This probably differs between the different arenas but in this study the focus is on the training of tactical decisions on the land arena.

There are similarities between the land arena and amphibious operations as well as the elements of protections of bases that occur within the Navy and Air Force. It is possible that knowl- 
edge of other arenas thinking and considerations could also be relevant for tactical training in other arenas when it comes to understanding how they use geography, weather and technical systems to their advantage.

Langefors also pointed out that the time you have at your disposition, to read, understand and analyse the situation, affects the amount and quality of data required and the extent to which data must be fully analysed or requires a very experienced and knowledgeable user. In order to facilitate the analysis in a short period of time complete classifications, e.g. for accessibility are needed. This can be done by pre-classifying areas and either visually highlighting areas more or less passable with colours, patterns or symbols, or put these classifications in the map database for internal calculations (see Figure 3 ). The problem is that these become static classifications that only apply to known vehicles and properties that the original calculation was made for. Similarly, you could insert zones for connection, effect, concealed advance or radar coverage with known parameters. For basic training, it is possibly enough to assume such finished classifications. It is also likely that the system used in a gaming situations currently, is not able to calculate dynamically changing characteristics of the battlefield or even of the various parties 'abilities' but needs to focus on the agents' decisions and actions of the pre-determined game situations.

Purely philosophically one can always argue that it is not possible to prove that a particular analysis is correct, and ensure that it is possible to drive through, or in another way within the corridors and with the parameters the program suggests. On the other hand, one can with the same starting point produce maps of areas where it is most likely not possible to get around with known vehicles. In this way one can identify which areas need to be examined more thoroughly to obtain greater significance to make tactical decisions in the conflict zone. This is described in the earlier mentioned work on "Criticism Systems" [3].

In the future it would be interesting to be able to calculate the capabilities and how they would change with other equipment, or other vehicles or temperature, rainfall and other factors that are different than in the original analysis. This requires that one must solve the representation of interesting scenery objects in a different way than in the classic war game. An alternative is to have a dynamic classification in a Geographic Information System (GIS) with the basic parameters such as topography, soil type, afforestation, hydrology, temperature for a longer period of time, etc. and perform the analyses in parallel and near real time. Calculations of radar ranges, fire control, radio coverage, etc. can also be calculated in the GIS-based system for operational use, which manifests itself in several reports of using GIS for targeting [7] for general Military activities [7] and using meteorology in transport planning [8]. In this way one can achieve the greatest possible information without burdening the user with complex calculations.

Upon collection of signals from GNSS (like GPS) satellites GIS systems can calculate and correct incorrect positions faster and better than humans. The position information must then be merged with background maps or charts to determine where on earth you are positioned. The information can also be automatically fusioned with information about what areas are mined or within detection and shooting distance from the enemy. How one then tactically handles the situation is an important task for humans. But even here we can have good use of computers, according to Kahneman [1], that both can count on and statistically verify or falsify the prejudices that our "Cognitive System I" often reacts with. These prejudices or preconceptions pose problems in decision-making based on flawed foundations. If we are not trained to deal with the situations we are likely to end up in (according to Kahneman) a "gut reaction", a panic behaviour, or a denial of danger, with the potential risk being overlooked. For us to be able to leverage the rapid cognitive systems in a successful manner requires extensive education and training. On the other hand, our more analytical "Cognitive System II" is both sluggish and slow and needs all the help it can get from decision support systems.

\section{THE NEED FOR GEOGRAPHICAL DATA}

These are the geographic data pointed out by the tactics teachers in the Swedish Army Land Warfare Centre (MSS) as being of the greatest significance for tactical decisions. Much of the data suggested as essential to analyse the tactical behaviour are developed by the Swedish National Land Survey (NLS) and the various authorities involved in the Swedish Geo-Data collaboration. Other more specific data are from The Defence Forces, Swedish Civil Contingencies Agency (MSB) and the NLS joint mapping function for civil and military purposes GeoSE. Furthermore, there are volumes of data collected by private and public companies and organizations that need them for other purposes but could be of potential use in defence and crisis management.

Suggested Data divided into data class $->$ data type -> example application $->$ additional comments

\section{Basic Data}

a. Topography

i. Height Advantage analysis

I. Even the input data in models for estimating soil moisture along with other basic data are a component of accessibility analysis

b. Gradients

i. Advance forward

ii. The gradients length is also important for several analyses of trafficability

II. Aspect (orientation of the compass)

i. The exposure, light

ii. Even for assessing frost and soil moisture as well as vegetation $>$ accessibility

III. Ground type

i. Soil type (including size, shape of the particles, minerals, mixing/stratification) soil depth

ii. Soil conditions, carrying capacity, 
IV. Water
a. Depth
b. Width
c. Direction of flow and power
d. Ford, seabed and slopes

V. Vegetation
a. Vegetation types
b. Summer / Winter
c. Vegetation height
d. Vegetation density
i. Sight, screen, protection, grouping

VI. Local knowledge, in urban warfare
a. Building heights
b. Building materials
c. Structure (distance between buildings, roads, etc.)
d. Urban complexity
e. Important /protected buildings
f. Population

VII. Roads
b. Road network
c. Topology
d. Capacity, buoyance, surfaces
e. Curves
f. Hilliness

i. Advance planning, threat analysis

ii. Constrictions, vulnerable sections of road,

iii. Hidden advance, control, observation, network analysis, transport and route planning,

iiii. Am, propellant and other supplies transport opti-

\section{Derived Data} mization (TOLO)

a. Soil conditions for different vehicles inching across country,

b.Field of vision, forward observation post,

c. Robotic window array

d.Radar and communications planning

\section{THE NeEd For Geographical Data}

The analysis carried out is dependent on both the available data and the models for analysis that have been used. Thus, it is important to have enough basic data and validated models for analysing both strategic decisions on the objective of the mission and the tactical decisions on implementation. In a civilian project in Eskilstuna municipality where the construction of a new attractive residential area was to be placed close to the Eskilstuna River; local politicians requested support in the planning process. A traditional flood risk model showed that it would be possible to build at the shores of the river; but the improved model that was developed rejected the location and the decision was therefore to put homes at a higher located area and make a park in the proposed residential area adjacent to the river with discovered elevated flood risk.

It is also important to draw developed conclusions of the analyses made. When developing a model for calculating the off-road mobility one must also consider how important existing roads are for the control of a geographic area.
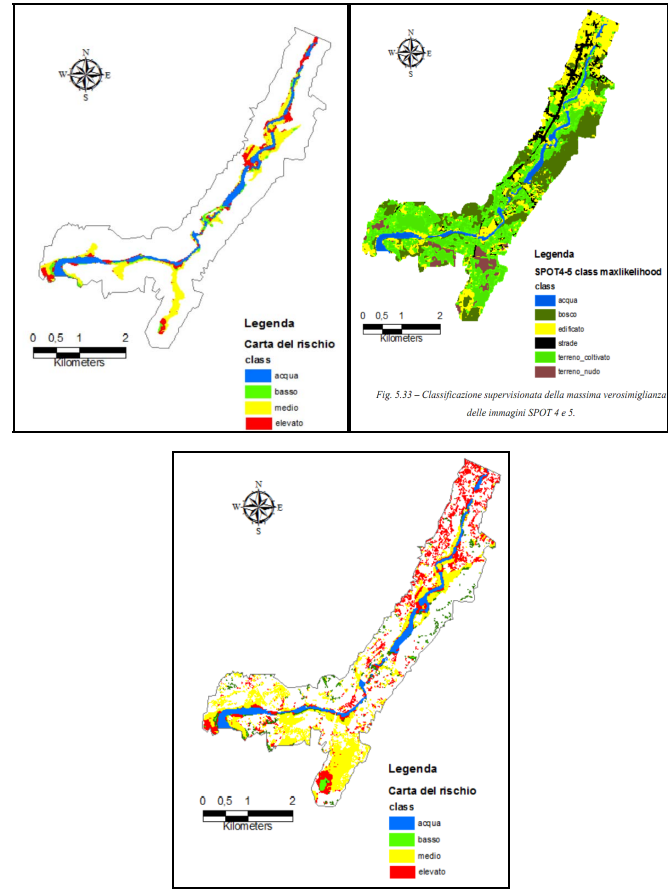

Figure 2. Upper left; traditional flood risk map. Upper right; an additional satellite based scene with vegetation and down; a new flood risk map based on higher resolution data and improved model.

The maps in Figure 3 show, in addition to possible/impossible off road tracks in the terrain, the importance of the existing road to stay open to both a military actor and the head of the emergency services at a major forest fire. The discovery of channelling terrain also demands to extend the analysis to a larger area in order to understand the consequences of different scenario

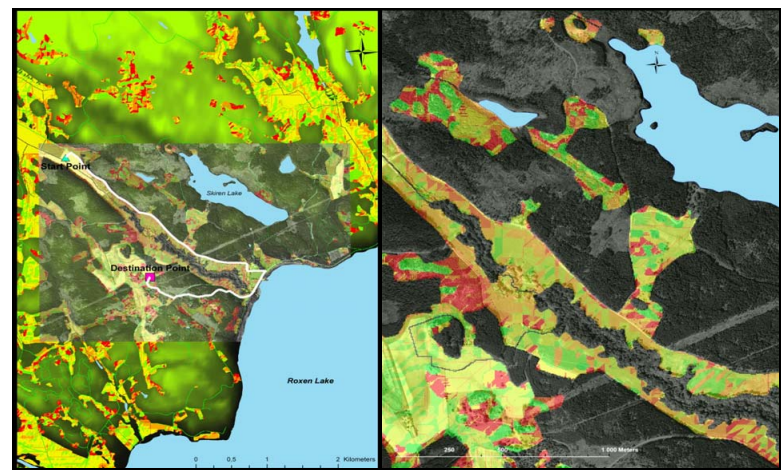

Figure 3. To the left possible road and to the right a classification of how difficult it will be to go through the road-less terrain.

The analyses in Figure 3 are relatively fast to implement if the data are available in the right format and quality, and that there are models developed for analysis of useful and practical geographic information systems allowing data and sensor fusion. In this way, the planning process has served as a learning activity that can be supplemented by references to areas and 
situations that require you to visit and examine the sites more carefully and maybe practice to validate the analyses. There will probably also be a need to make decisions on imperfect data in spite of the analysed information as it is dependent on the events developing in an unpredictable way. If on the other hand, a large part of the information is present and can form a more stable basis for decision making and perhaps also together with the opportunity to practice different situations in a geographical area, the uncertainty becomes less than if one knows nothing or very little about it.

.. "There are known knowns; there are things we know that we know.... that is to say there are things that we now know we don't know. But there are also unknown unknowns-there are things we do not know we don't know" Donald Rumsfeld ${ }^{2}$

\section{REEDING THE LANDSCAPE AND THE MAP}

Being able to "read the landscape" is an important skill for the person who will perform both military and civilian operations and activities there. This applies to both the natural landscape as the man-made or transformed landscapes such as cities and other sites. Various physical processes affect the landscape depending on the set of landscape elements such as various types of ridges - sand ridges and sand /moraine formations which naturally are drained and therefore passable. The sides are however often moisture-laden and muddy from additional water and clay particles from the ridges gathering there. The bottoms of the valleys have, for the same reason higher soil moisture and vegetation as well as several blocks of rock. This is dependent on which province you are in, what type of bedrock exists and other causes, such as how old the bedrock is and if the loose soil layers are eroded. Channelizing terrain is the interaction between topography, hydrology, forests, soil conditions and man-made structures, and forms one of the key factors for both one's own and the enemy's mobility. These conditions also affect the possibility of grouping. This will influence decisions on both the outcome of protection and can have decisive importance for maintenance and other logistical issues.

Accessibility therefore depends not only on the specific characteristics of the site, but also with respect to effect and protection. The enemy's potential ability to take action and match the technical systems that are available is of the utmost importance for him to overcome these frictions.

To read the map can be done partly by studying the different landscape elements the cartographer decided to put on it. Further by analysing the various objects and their relationships, and what properties the objects have. Preconceptions of various natural processes are important so as to be able to predict how the landscape will influence on the situation. Symbols and icons can describe different objects and their properties, but require a deeper knowledge of how the classification of these is made in order to take informed decisions. Informa-

\footnotetext{
${ }^{2}$ Donald Rumsfeld from DoD News Briefing, February 12, 2002
}

tion about the spatial data and how they have been collected and for what purposes, are important metadata that should be a part of the various databases. Attribute data that describes the classification of data, and under what method or model is important information for indexing databases so that they can be merged. Deviated classifications and attribute tables, or if the basic model of the databases differs, translation tables or active mediators (middleware) must be developed that allow for the use of data in cross-sectorial and interdisciplinary applications. Soil types can, for example, be classed according to an agricultural perspective, based on the buoyancy for construction, environmental protection, etc. In order to use these data for military needs, we must then eventually translate the database attributes to suit the specific research question. Data representations are also important. Common formats include vector data in the form of points, lines and surfaces as well as GRID cells or tessellations. Further on, triangulated data described as triangles or other regular or irregular tessellations such as hexagons or rectangles are illustrated.

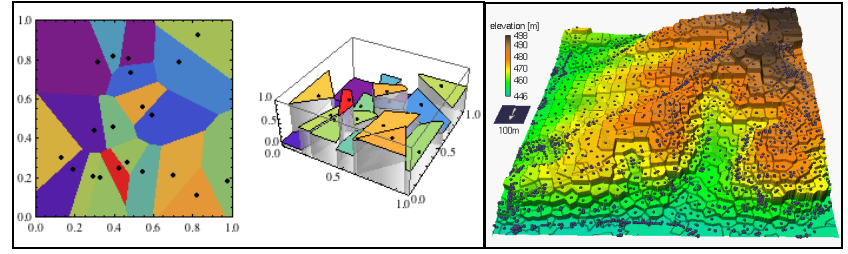

Figure 4. Example of irregular tessellations

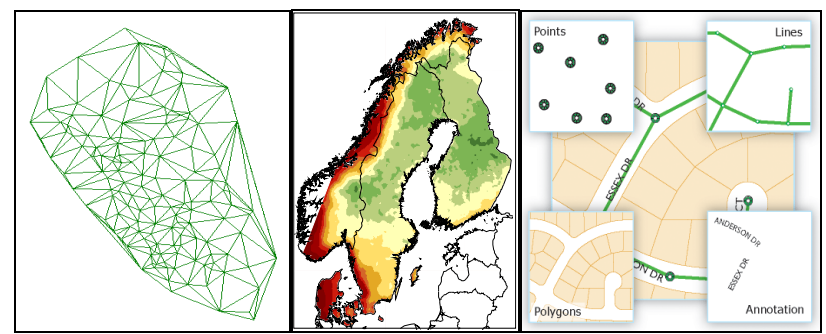

Figure 5 Left examples of triangulated map data, in the middle a regular GRID and to the right vector representation of points, lines and areas (polygons). Note that annotations can be made with attribute data associated with both vector elements and to the grid cells in the GRID format.

In addition to the differences in representation - that may depend on the method for data capture (the way the map data have been collected) - the purpose of collection and the basis on which classification has been made - the data must be harmonized so that different databases can be compared with each other or fusioned/merged.

Knowledge of our own geography is thus one of the keys to success as long as we are in known areas. If we are supposed to implement actions in other geographical areas or climatic zones this will require thorough training to successfully play with these factors.

Knowledge of the Swedish provinces includes, for example, information on forest areas that cover large parts of the country. Forestry uses many different methods of data capture. All private logging roads are, for example, mapped even if 
they are not presented on the official maps. Often there are attribute data associated with the digital road data with road classes that indicate buoyancy and mobility for long and heavy vehicles. The extent to which road classes contain information that makes it possible to calculate the road endurance for many vehicles; in convoys or heavy tracked vehicles are questions that must be answered, before the databases can be used in applications for supporting a safe society, security and defence!

Forested land is partly classified to enable site quality calculations i.e. expected productivity. Site usability for forestry is calculated based on soil type, soil depth, topography, aspect, soil moisture and hydrology to name but a few. During one period, the site usability was reported without access to the underlying variables. This has then become a problem when the market for different types of forest products changed or harvesting methods improved so it was possible to get around in areas that previously hampered harvesting. The use of distributed databases is a method to allow reclassifications that are adapted to the new conditions. The Armed Forces must investigate the extent to which these inputted variables are available for calculating more adapted applications.

The actual forest with tree species, tree height and biomass are today surveyed by LiDAR scanning or from other aerial or satellite remote sensing. LiDAR scanning can also provide ground conditions under the trees crowns by recording and analysing so-called second-returns. From those return signals possible ditches, large stones, or other barriers to logging or accessibility can be discovered. You can also access information necessary for planning optimal placement of logging roads, based on the desire to harvest valuable trees and thus be able to build the road at the lowest possible cost.

With the standard LiDAR system a resolution of a few decimetres will be possible and measurements of railroads or other objects can be achieved with a significantly better resolution. These methods are now standard at many forestry companies, road authorities and others with the responsibility for infrastructure in Sweden. Coordination has been made in terms of creating a national elevation database based on the LiDAR data and 2 meters contour interval. Vegetation data are not available in the database and readings of every other meter makes accessibility analysis limited in many areas. Also Finland made a national scanning of the forested areas in the whole country that is then available to various stakeholders, both governmental and private. An investment in higher resolution and combined with different spectral remote sensing data would contribute a much more useful database [10].

\section{A. Topography}

Topographic data is available for the entire earth with about 50 meters equidistance (the distance between the measurement points). Radar sensors on satellites have produced these data.

In Sweden, it was felt that elevation data was needed with better resolution and higher accuracy, and that is why a database with 2-meter resolution is being created.

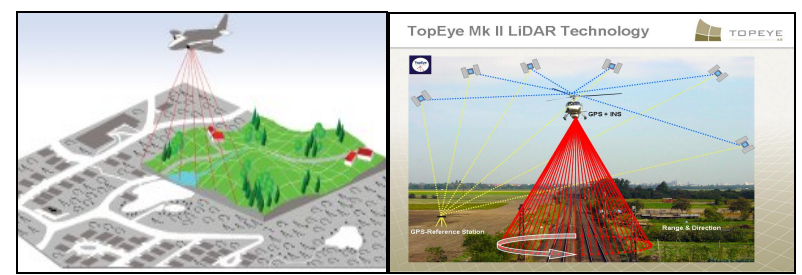

Figure 6. LiDAR (Light Detection And Ranging) is an optical remote sensing technology that can measure the distance to, or other characteristics of a target by laser light beams. LADAR is not correct because it does not use radar or microwaves to detect/create images over objects on the Earth's surface.

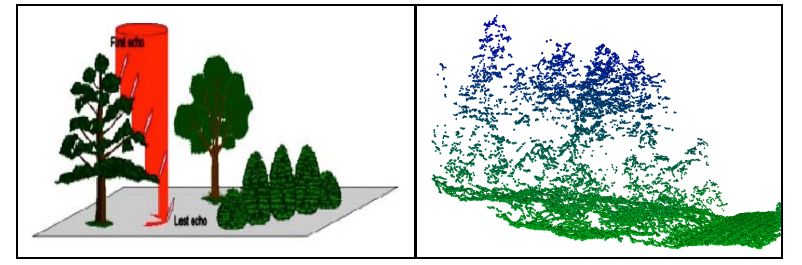

Figure 7. The reflected light-rays create a point cloud that can be modelled and analysed. By "multiple returns" different parts of the tree tops (crown of the tree) and their height can be measured, as can conditions on the ground.

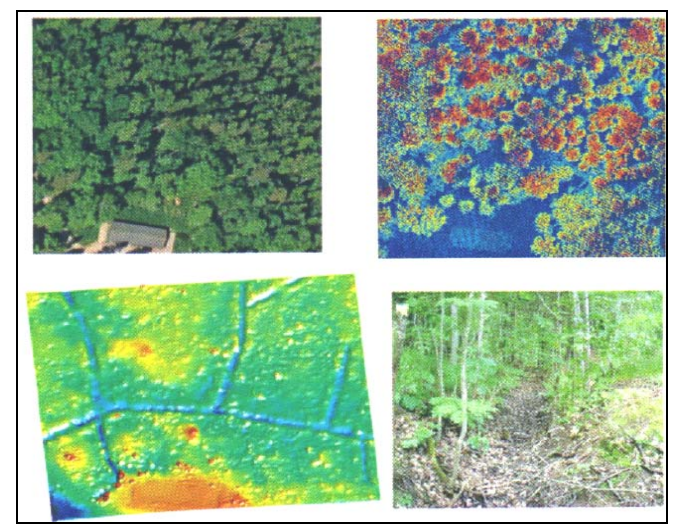

Figure 8. The upper left image shows a traditional digital colour photo of a forest. The next image the heights calculated in a LiDAR registration and the lower left shows what is found under the trees. This is also documented with a photo in the bottom right picture.

The database, however, does not have sufficient resolution to be used with precision weapons like the Excalibur, which requires at least 1-meter resolution [11]. Traditionally, topography has been represented with contour lines on analogue maps. Making topographic calculations in a GIS, however, a grid structure is better. As heights are represented in GRID cells a GIS cannot only quickly figure out where channelizing terrain is present, but also the slopes, slope lengths and aspect of the slope. This supplemented with vegetation and other objects can be used to calculate the field of vision, plan the radio connection, radar coverage and barriers, hidden advance, risk of flooding of camps or installations, etc. 


\section{B. Vegetation}

The vegetation can be mapped with high resolution using LiDAR. In LiDAR data can different tree species, tree height and volume as well as the ground beneath the trees be analysed. All this is important in order to calculate the accessibility but also cover and protection. Other methods for vegetation mapping create more general descriptions, often in the form of a generalization of trees or other vegetation in different areas. Such a simplified classification is quick to assimilate and incorporate into the analysis but because the data are generalized, significance becomes lower. Moreover, it is difficult to assess the vegetation and land with traditional remote sensing. With other sensors such as radar it is possible to map the land, and to some extent, the area under the trees, and with IR (Infra Red) sensors, it is possible to determine what tree species are growing. With Multi-spectral remote sensing can be analysed how much biomass is available in a particular grid cell on the ground by counting the difference between the wavelengths of the analysed spectrum that for example represents chlorophyll reflection and absorption. If you have previous registrations you can, in theory, analyse if a forest has been exposed to something that affects the vegetation. Nitrogen-rich substances commonly found in explosives can benefit vegetation, but exposure to copper and other substances inhibit vegetation. With hyper spectral sensors one could also detect camouflage that is unable to be seen in the visible spectrum but which differs in other narrow spectral bands that the sensor can register.

\section{Hydrology}

Hydrological parameters play a major role in many of the military capabilities. In addition to the great rivers and lakes, which require amphibious capability to pass, as constituting soil moisture and groundwater hydrology gives important parameters for the understanding of landscape characteristics. Hydrography can be mapped using remote sensing and to some extent you can also map the shallower bathymetry ${ }^{3}$ with the help of helicopter-borne LiDAR. The flow and direction of streams and rivers, as well as shores and the land conditions around watercourses are factors that often must be verified on the spot but possibly could be mapped based on remote sensing data and aerial photographs.

There are a lot of hydrological measurement data that are generated for models and the monitoring of rivers for the use of hydro power plants, or for municipal water supply. This information would be valuable to include in a military geographical digital atlas and the principles and consequences would be important to train for in relation to tactical considerations. Soil moisture can be measured by remote sensing and complemented by calculations if there is a topographical model with information on soil types and soil depth, vegetation and aspect ${ }^{4}$.

Knowledge of the weather situation for a longer period may be required to obtain meaningful classifications of soil moisture; and if you need to take into account frozen ground,

\footnotetext{
${ }^{3}$ Measuring the depth in lakes, seas and other waters

${ }^{4}$ An objects orientation according the compass
}

or get information about frost damage from melting snow and spring thaw.

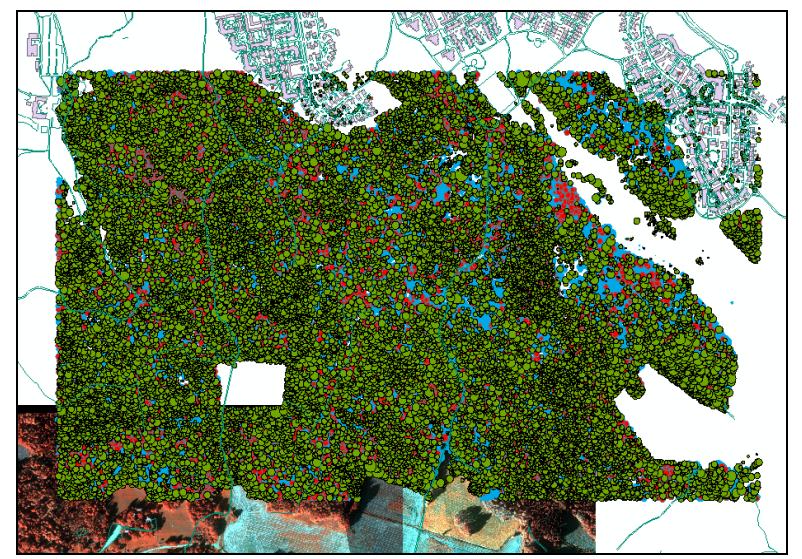

Figure 9. Each tree is identified in LiDAR and represented by a vector circle that describes the tree size and a colour to describe tree species. Also height is registered as an attribute in the GIS database but not illustrated here. Underneath is the hyper spectral image that is registered in the 235 narrow spectral bands and this is false coloured in RGB (Red Green and Blue additional colour coding). By comparing the trees with the underlying spectral signature one can then assess if the tree is under stress due to drought, diseases, parasites or other influences [12].

Groundwater can in Sweden be calculated using the well archive Swedish Geological Survey (SGU) holds. There is information on the well capacity, and the different geological strata that has been drilled or dug through and the depth where it has accessed water. Even the quality of the water is registered, which can be used for the calculation of a source's endurance against drought and pollution.

Rivers and streams are preferably represented as vectors, thus allowing data to be indexed topologically as well as the direction of flow and other factors which impact different sections of the streams. Wells in the shape of points and ground water content as surface covering polygons or as grid, is advantageous if the data are to be used for analysis along with other data.

\section{Geology}

The bedrock and its different shapes and characteristics as well as the soil layers shapes and properties, are important for military operations. The topography consists largely of mountains, ridges and valleys in between, which are significant for tactical decisions and the ability to observe and operate. By mastering a number of heights can in turn affect an antagonist opportunity to operate which will contribute to one's own freedom of action. Solid rock is also important for fortification. How the soils have been formed, from which minerals, if they are mixed with organic matter, salts, etc. determines which properties they may have under pressure, load and with different soil moisture. Some clay, which also occurs in Sweden, can move from solid to liquid (called liquefaction) if exposed to shocks or explosions which is not unusual during military operations. 
Both hydrologists and quaternary geologists describe different types of wetlands. These wetlands exhibit different behaviours when exposed to mechanical stress. Traditionally, the Swedish maps have a dozen of different wetland classes, which we are dependent on, while they from our perspective, are crucial factors. Other countries' maps have perhaps only one or a few wetland classes, and this situation decreases the opportunities to make relevant tactical assessments of both accessibility as well as other military capabilities. This is another example of different ontologies that must be taken into consideration when you want to use the data for military analyses. One way to handle this is to register the various parameters that make up a class of phenomena. This would mean taking into consideration the soil type's grain size, the mineral the soil particles or sand consists of, how the grains are formed; if it has been formed through fluid processes in rivers, in the sea or during the ice age, if there is organic material in the sand or soil, moisture, thickness, etc. If you have these qualities and know the conditions applicable to the proposed activity you can more easily make a classification that is suitable for these purposes.

\section{E.Meteorology}

Meteorology often interacts with the landscape's geographical situation as rainfall is for example affected by topography and afforestation. In turn, the land and waterways are affected by meteorological parameters as rainfall, temperature etc. so this duality is something you have to manage both with regard to accessibility, impact, and protection. Many sensors are affected by rainfall (often negatively for those who want to use sensors for reconnaissance but positively for those who would like to advance undisturbed). There is still much work needed to harmonize the different formats for maps used by meteorologists and geographers but one could achieve a mutual exchange of data between these different professions and this would probably culminate in a win-win relationship with the ability to make better tactical decisions. Better topographical information would probably also provide meteorological forecasts that would be more specific in regard to which areas will be affected, as well as higher reliability in wind, temperature and precipitation data or forecasts. [9][13].

\section{Conclusion}

Tactical decisions are really important in military affairs both for offensive and defensive actions. Some of the main factors that affect the success or failure are related to the possibilities to understand and use the geographical conditions and the weather in the planning and for tactical and operational decisions. Then it is also to note that a disadvantage for the own troops can be turned to a benefit if the conditions are even worse for the enemy. Earlier the officers and troops were trained in the areas where they were supposed to operate.

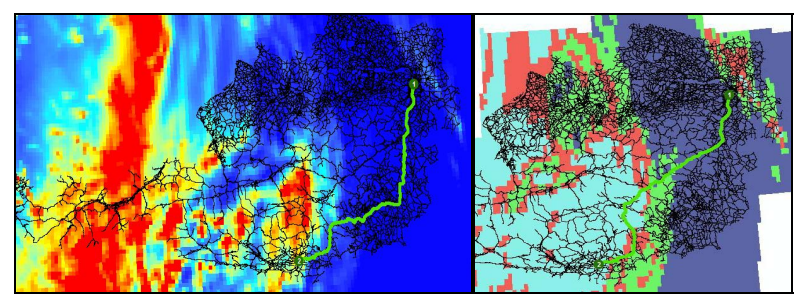

Figure 10. Meteorological data or forecasts to support transport planning and calculations of other tactical parameters [9].

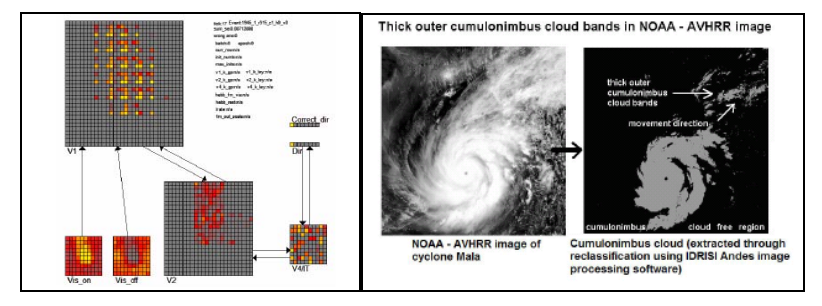

Figure 11. Use of "Artificial Neural Network" analysis to calculate tropical storm paths based on Satellite Scenes (NOAA AVHRR) on a standard PC - using Parallel and GPU programming and analysis [13].

This is much more rare today with smaller armies and less resources in many countries (whereas military expansion and development is huge in others). An alternative is then to systematically analyse the different landscapes and train different scenarios in simulators. Some answers to the questions about what data and analyses that should be included in such training have been given here. To the natural landscapes and the landscape elements they have, should also the urban landscapes be mentioned as a much more likely area for conflicts and fights. The dependency between the societal facilities like roads, railways, airfields, water and sanitation systems etc. and what the requirements should be if those were lost is discussed as an important judgment of priorities to protect. In the theories about planning under time pressure is suggested that a limited numbers of factors should be considered in tactical planning [11]. To be able to do so and make informed decisions the staff must have a complete education and training based on analysed maps and preferable - in training systems (simulators) that support the judgements with predefined models and data and possibilities to present different scenarios to decide the tactical behaviour on. The exercises must - according to Kahneman support the cognitive areas where humans are least skilled. If the training is supposed to support the different military abilities in a certain region it would also be beneficial to use real conditions in those areas and the geographical features that are necessary to analyse and understand to take tactical and operational decisions. In this way it could be possible to train, prepare and be alert for action especially in the relevant geographical areas but also in general. 


\section{ACKNOWLEDGEMENT}

Many suggestions for relevant data essential to analyse the tactical behaviour comes from the Swedish Army Land Warfare Centre (MSS) and are developed by the Swedish National Land Survey (NLS) and the various authorities involved in the Swedish Geo-Data collaboration. Other more specific data have been delivered by GeoSE - a common function between Swedish Defence Forces, Swedish Civil Contingency Agency (MSB) and the NLS. GeoSE have a joint mapping function for civil and military defence purposes. Furthermore, there are volumes of data collected by private and public companies and organizations that need them for other purposes but could be of potential use in defence and crises management. Thank you all for providing us with data and advice!

\section{REFERENCES}

[1] Kahneman, D, Think fast and think slowly, Volante publishers, 2012

[2] Langefors, B., Essays on Infology. Chartwell W Bratt. 1996.

[3] Sivertun, Å. Critique Systems for Geographic Information and GIS. Proceedings at the 24th International Cartographic Conference ICC 2009 Santiago, Chile.

[4] Brehmer, B., Command Without Commanders In: Proceedings of the 14th International Command and Control Research and Technology Symposium, 2009

[5] Alberts, D.S. (2007) Agility, focus and convergence: The future of command and control. International C2 Journal, 2007:1, 1-30..

[6] Brehmer, B. (2007) Understanding the functions of $\mathrm{C} 2$ is the key to progress. International C2 Journal, 2007:1, 211-232.

[7] Rutgersson, LG., Eliasson, P., \& Sivertun, Å. Rapid mapping for precision targeting. UGI 2011. Santiago, Chile, November 14-18, 2011

[8] Sivertun, A. Military Geography and GIS as part of Military Engineering, Royal Military Academy of Sciences No 1, 2012.

[9] Litzinger, P., Navratil, G., Sivertun, A., Knorr D., Using Weather Information to Improve Route Planning p. 199 - 214. In Bridging the Geographic Information Sciences: International Agile'2012 Conference, Avignon (France), April 24 -27, 2012. Lecture Notes in Geoinformation and Cartography Authors; Jérôme Gensel, Didier Josselin, Danny Vandenbroucke Editors Jérôme Gensel, Didier Josselin, Danny Vandenbroucke. Springer, 2012ISBN3642290620, 9783642290626

[10] Lindgren, N., Nilsson, B. Allard, A., Åkerholm, M. Christensen, P. \& Olsson, H. (2014). Method development for data collection in the NILS landscape square - Estimates of laser data and optical satellite imagery. Umeå: SLU (Working Paper 429, 2014)
[11] Thunholm, Peter (2003). Military Decision Making and Planning: Towards a New prescriptive model. Diss. (Summary) Stockholm: Univ., 2003

[12] Sivertun, Å., Zöphel, K., Ahlberg, S. (2014) LiDAR and hyper-spectral data for Landscape and Vegetation Classification and Monitoring (Proceedings at iEMS San Diego 2014)

[13] Roy, C., Kovordanyi, R., Raquib, A., Gumos, A., Sivertun, Å. (2006) Cyclone Tracking and Forecasting in Bangladesh Using Satellite Images without Supplementary Data. Editor: Petri Takaka, National Land Survey of Finland Proceedings of the Nordic GIS Conference second-4-10.2006 Helsinki, Finland ISBN 951-29-3082-X (printed), ISBN 951-29-3083-8 (PDF) 